\title{
Situating Augmented Reality in the K-12 Classroom
}

\section{Ms. Te'Airra Monique Brown, Virginia Tech}

TeAirra Brown graduated summa cum laude from Norfolk State University with a Bachelor of Science degree in Computer Science Engineering. Currently, she is a second year doctoral candidate in the Industrial and Systems Engineering department at Virginia Polytechnic Institute and State University. TeAirra has received numerous fellowships and honors, which includes: NSF Graduate Research Fellowship, Gates Millennium Scholarship, New Horizon Graduate Scholarship, Bradley Electrical and Computer Engineering Department Fellowship, GEM Consortium Fellowship, Dozoretz National Institute for Mathematics and Applied Sciences (DNIMAS) full-academic scholarship and a suite of other honors. TeAirra's research interest focuses on developing and evaluating augmented reality (AR) applications to support ARbased learning experiences in K-12 classrooms. She wants to identify the unique benefits and challenges in pairing personalized learning and augmented reality.

\section{Ms. Glenda Young, Virginia Tech}

Glenda Young is a third year PhD Candidate in the Department of Engineering Education at Virginia Tech. She is from Starkville, MS where she attended Mississippi State University (MSU) and earned a Bachelor of Science in Industrial Engineering. She also earned a Masters of Industrial and Systems Engineering from Auburn University (AU). Glenda is a Gates Millennium Scholar and her research interest include academic/industry partnerships, student transitions, and broadening participation in engineering. 


\section{Situating Augmented Reality in the K-12 Classroom}

\section{Introduction}

National dialogue and scholarly research illustrate the need for science, math, technology, and engineering (STEM) innovations in K-12 environments ${ }^{[1]}$. President Barack Obama affirms this need by stating, "... Leadership tomorrow depends on how we educate our students todayespecially in STEM." In response, there has been an increased use of technology in the K-12 classroom setting to stimulate interest in STEM fields, e.g. ${ }^{[2]}$. One way technology is introduced in the K- 12 classroom is through collaborations with post-secondary education. In engineering, faculty and graduate students often engage in outreach activities with K-12 to increase student exposure and understanding of engineering to promote the engineering career pathway.

Considering the breadth and depth of engineering, various technologies have been introduced to enhance content delivery and further improve the student learning experience. One application of technology that has been used in K-12 settings is augmented reality (AR). AR technologies project virtual objects onto real world scenes. For example, Construct3D is an application designed to deliver mathematics and geometry concepts to high school students through augmented construction scenarios. Although Construct3D researchers cited improvements in students' spatial skills, robust conclusions about the impact on learning could not be drawn because the application lacked a theoretical basis in educational research. Similarly current AR application literature highlights researchers attempts to evaluate and measure student learning in AR applications with little basis in learning science or educational psychology literature ${ }^{[3]}$. Research is needed to better understand how different learning theories can be used to inform implementation of AR applications in K-12 environments. Doing so, allows researchers to consider the teacher's and student's role when evaluating the usefulness of AR applications.

One explanation for the design of AR applications with little basis in learning theory is the disciplined focused training of post-secondary engineers. Engineering faculty and students have great technical depth in an engineering discipline but sometimes lack training in educational research. This knowledge differential may lead to the design of technology interventions that are not embedded in concepts of knowing and learning. It is important to acknowledge that as the field of engineering education matures, post-secondary engineering faculty are gaining more exposure to educational research studies guided by various learning theories. Even so, because there is a great deal of focus on bringing technology into the classroom and engineering faculty are involved in curriculum design and engineering outreach content, it is crucial that the instructional design supported by AR applications be based on learning theory [4].

Engineering education researchers, Newstetter and Svinicki ${ }^{[4]}$, offer engineering faculty and graduate students a "primer" of three conceptual frameworks that present learning theory to engineers in an approachable way, with examples of how the theory can be used to influence post-secondary instructional design. We suggest that post-secondary engineering educators should also follow these recommendations as they develop technology to be used in the K-12 environment. 
In this paper, we create a guide for how one conceptual framework discussed by Newstetter and Svinicki can be used to incorporate an AR application to teach engineering concepts in K-12. We leverage the situated framework to outline how situative learning theory can be used to design instruction to teach electrical engineering concepts in a fourth grade classroom. Situative learning will allow us to evaluate how learning can take place within the context of a classroom by using virtual information. We outline the role of the student, teacher, and AR application; exemplify class activities and assessment; and discuss the purpose of grading within the situative framework. Using literature and curriculum from TeachEngineering.org ${ }^{[16]}$, we will offer a guide for engineering educators to design an environment in which situative learning theory leveraged with AR applications can simulate real world problems that support measurement of student learning outcomes.

First, we provide a brief review of the literature as it relates to augmented reality and situated learning. Then, we outline guidelines for using seven instructional components as they relate to the situative framework. We complete the guidelines by providing an explanation of how AR technology supports the instruction of engineering concepts in a fourth grade classroom. We conclude by discussing implications for student learning and engineering educators. The guidelines presented in this work are grounded in situative learning theory, and can be easily transferred to other grade levels. The example application in this paper can be used as an outline for other grades levels; though the application will need to be adapted to accommodate specific grade level learning objectives and subject matter.

\section{Augmented Reality}

Coined by Professor Tom Caudell, AR has existed for over thirty years in various forms. It combines the real world with virtual interactions by overlying 3D images onto real objects. Users of AR technologies can see the real world with the addition of computer-generated images opposed to virtual reality where all the users' interactions are simulated. In contrast to being fully immersed in a virtual environment, AR users' are aware of their surroundings and interactions with the physical world. The utilization of AR can enhance real life with artificial images ${ }^{[5]}$. Along with enhancing life, it can bring new dynamics to industry, academia, and government sectors.

While AR has existed in several forms for quite some time now, it has yet to be fully embraced as an assistive tool for learning in academia. The usage of AR in education has been inserted in many subjects e.g., 3D representation of cells in biology, displaying molecular structures in chemistry, and solving puzzles at museum exhibits in history. Researchers believe that education can profit from AR development because any subject can be more colorful, interesting, and interactive. The 2005 EDUCAUSE Learning Initiative acknowledged that the use of augmented reality in the educational setting could possibly make the learning experience much richer. This technology offers great promise by leveraging the unique blending of real and virtual worlds to produce new educational opportunities ${ }^{[9]}$. Some of these opportunities could potentially provide rich, contextualized learning for understanding concepts related to mathematical education.

There have been several studies that evaluate AR applications on student motivation and 
learning. According to O'Shae, AR has the potential to enhance student motivation, involvement, and excitement due to the active role it allows the students to encompass. Additional to increased engagement and learning, AR experiences could provide positive impacts to the cognitive process if it is well designed ${ }^{[9]}$. Another advantage of AR is students' ability to learn about the concepts and environment around them without being removed from the classroom ${ }^{[11]}$.

While student evaluations suggest positive experiences with AR, learning outcomes have been difficult to measure because the applications lack grounding in educational theory. Some researchers have addressed this dilemma. Larsen and researchers analyzed the pedagogical effectiveness of an augmented reality system in a science course to better understand concepts ${ }^{[10]}$. The 5E model of instruction, based in constructivist learning theory, was used to compare an augmented reality system to traditional presentation methods. Their results stated that the pedagogical effectiveness was very positive rated and the use of AR raised students' interest which increased the majority of participants learning of science concepts. Still, the majority of current AR literature reflects the prior point: researchers' attempts to evaluate and measure student learning in AR applications has little basis in learning science or educational literature. We believe our guide will add to the literature by designing AR applications within the situated learning environment.

\section{Situated Learning}

Situated learning theory is based in the situative conceptual framework and examines how learners gain knowledge through social contexts and interactions with materials and people. When discussing theory, it is important to understand the nature of knowing and consequently what signifies learning and how such views impact instruction and shape the course environment [4].

Knowledge is viewed "as distributed among people and their environments, including objects, artifacts, tools, books, and the communities of which they are a part ${ }^{[12]}$." Knowledge moves beyond individual construction to incorporate the impact that the environment has on how an individual conceives and experiences learning. Learning is signaled by an individual's meaningful participation in a community of practice. Progressive participation can be described as more effective or more meaningful contribution to the community over time ${ }^{[12,4]}$. An individual learner variably moves across observation, participation, and contribution roles within the community.

Engineering instructional design aligns well with situative learning theory based on three characteristics of the field. Engineering requires use of representations, aligns with professional practices, and has a strong emphasis on design ${ }^{[13]}$. For example, in an engineering design project, group activities create opportunities for students to form a community of learners while working to solve open ended problems. Students working to find a sustainable energy solution engage in research activities and team meetings where information is shared and negotiated among team members, and individual students walk away with knowledge they may not have acquired from individual studying or research. Situated learning theory recognizes participation in a community of learners as opportunities to increase student knowledge. 
Engineering educators serve to benefit from applying situative learning theory to the design of their instruction. Authors have recommended that engineering learning can be improved by focusing on teamwork and collaboration activities; engineering identity formation; student identities; role of representations; and use of tools while learning ${ }^{[13]}$. With proper guidance, engineering educators can use situative learning theory to address these focal points in the K-12 classroom.

We illustrate this by offering a guideline of how to use augmented reality application in a fourth grade classroom to teach concepts related to electrical engineering. The guideline follows a three part outline; we describe an individual instructional component as it relates to the situative framework; provide an explanation of how AR technology supports the instruction of engineering concepts; and provide a more tangible view of instructional design using a fourth grade lesson plan for teaching circuitry.

\section{Guidelines to Situating AR}

Table 1 summarizes the guidelines for integrating an AR application for teaching and learning electrical engineering concepts. We propose that following this guide, engineering educators can work with elementary teachers to incorporate AR into lesson plans to provide a more tangible and engaging environment for the students. First, we will review the three principles that summarize situative learning theory and will form the basis for the guide as suggested by Newstetter and Svinicki ${ }^{[4]}$.

1. Students should have opportunities to participate in the social and material practice of the targeted community. Since learning occurs as students progressively participate in the community, instructional activities should reflect the real world problems. In this way, learning occurs when students "interact with the tools, people, and physical world" to better understand the impact (pros and cons) and culture considerations of tools around them.

2. Students are encouraged to try on the identity of the community members.

3. Students should have the ability to create their own learning path. Projects and problems should be designed to allow students to explore multiple approaches and strategies but still arrive at needed outcomes. This often requires problems that are "rich and complex."

\begin{tabular}{|l|c|c|}
\hline Instructional Component & Situative Learning & AR Engineering Example \\
\hline Prototypical Instruction & $\begin{array}{c}\text { Learning occurs in a simulated } \\
\text { work setting of the community } \\
\text { of practice. }\end{array}$ & $\begin{array}{c}\text { AR application use graphic } \\
\text { information to explain } \\
\text { simulated circuit design in a } \\
\text { power outage. Shown in } \\
\text { Figure } 1 .\end{array}$ \\
\hline Teacher Roles & $\begin{array}{c}\text { The teacher may facilitate the } \\
\text { learning process, co-learn with }\end{array}$ & $\begin{array}{c}\text { Teacher can use the AR } \\
\text { application to illustrate circuit } \\
\text { component such as current, }\end{array}$ \\
\hline
\end{tabular}




\begin{tabular}{|c|c|c|}
\hline & $\begin{array}{l}\text { students, or evaluate the final } \\
\text { project. }\end{array}$ & $\begin{array}{l}\text { resistors, or power supply that } \\
\text { is otherwise difficult for the } \\
\text { student to envision. Shown in } \\
\text { Figure } 2 .\end{array}$ \\
\hline Student Roles & $\begin{array}{l}\text { The student role is to become a } \\
\text { larger participate in learning, } \\
\text { i.e. the student should move } \\
\text { from an observational role to a } \\
\text { contributing role. }\end{array}$ & $\begin{array}{l}\text { Interacting with augmented } \\
\text { simulations created by AR, } \\
\text { students will develop adequate } \\
\text { problem solving skills and } \\
\text { transferrable solving methods } \\
\text { to apply to new problems. }\end{array}$ \\
\hline Content Outcomes & $\begin{array}{l}\text { Students demonstrate that they } \\
\text { can operate within the } \\
\text { community with a full } \\
\text { understanding of the } \\
\text { "constraints of affordances". }\end{array}$ & $\begin{array}{l}\text { Along with the spatial } \\
\text { reinforcement, students will be } \\
\text { able to use the AR application } \\
\text { to solve problems similar to } \\
\text { power outages, understanding } \\
\text { the constraints of circuit } \\
\text { design. }\end{array}$ \\
\hline Class Activities & $\begin{array}{c}\text { The activities should create an } \\
\text { "authentic" learning } \\
\text { environment for students. }\end{array}$ & $\begin{array}{l}\text { During a hands on activity, } \\
\text { students will use the AR } \\
\text { application to build and } \\
\text { investigate the characteristics } \\
\text { of parallel and series circuits. } \\
\text { Shown in Figure } 3 \text {. }\end{array}$ \\
\hline Assessment & $\begin{array}{l}\text { Assessment occurs in the form } \\
\text { of reflections, e.g., portfolios } \\
\text { or journaling. }\end{array}$ & $\begin{array}{l}\text { While participating in class } \\
\text { activities and instructional } \\
\text { sessions, the AR application } \\
\text { will collect performance data } \\
\text { on the student to evaluate their } \\
\text { comprehension. }\end{array}$ \\
\hline Purpose Grades & $\begin{array}{l}\text { Qualitative feedback occurs } \\
\text { throughout the learning } \\
\text { process to allow students to } \\
\text { work through their difficulties. }\end{array}$ & $\begin{array}{l}\text { The AR application will be } \\
\text { programed to provide real-time } \\
\text { scaffolding in lessons. }\end{array}$ \\
\hline
\end{tabular}

\section{Table 1. Guidelines to Situating AR}

\section{Prototypical Instruction}

Instructional component: Learning occurs in a real world environment or a simulated work setting of the community of practice. Learning may also occur through a simulated environment as a representation of a real world problem. In this instructional component, the teacher will present the students with a real but theoretical problem. 
Classroom Illustration: For our proposed problem, teachers will ask students to imagine they are helping their parents decorate the Christmas tree. As they are preparing to hang up the lights, they realize that one of the bulbs is out. In an effort to fix the lights, the circuit is overloaded and the power goes out. The teacher will ask the students to think about a solution to this problem. In the profession, diagrams are used to teach engineers how to build circuits. Therefore, interpreting circuit diagrams is an essential skill for electrical engineers. In learning how circuits are built, students will understand how circuits are used to power devices and even light bulbs on the Christmas tree.

AR support: The AR application will provide students with information that can help them better understand the simulated circuit board design. This application will display graphical information onto physical objects in the classroom such as the electrical outlets and light switches to explain how different circuits would look under abnormal conditions. This will encourage the understanding and mastery of authentic environments that electrical engineers might encounter during a power outage. The benefit of creating a real world environment is an augmented perception of reality, as it exists in the present.

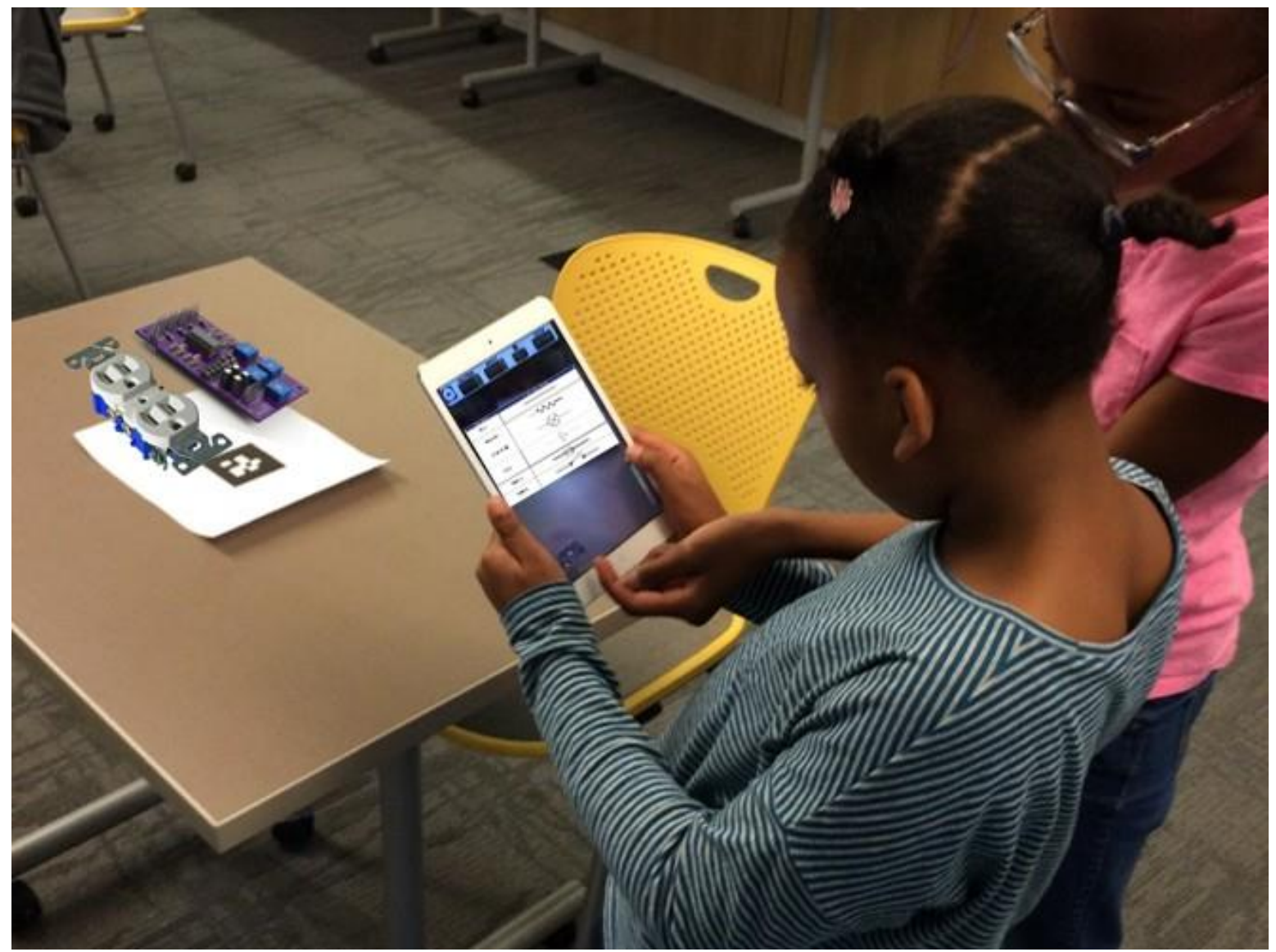

Figure 1. Students investigating electrical components in an outlet

Teacher Roles

Instructional component: In a situated AR experience, the teacher may take several roles, depending on his or her expertise. Primarily in K-12 environments, the teacher may facilitate the 
learning process, co-learn with students, or evaluate the final project. According to Shelton, to create more cognitively beneficial student engagement teachers need to find new ways of representing spatial relationships ${ }^{[6]}$. The exploration into novel areas using AR offers a new way for teachers to deliver abstract concepts to students.

Classroom Illustration: Teachers will bring local electricians and engineers in the classroom to talk about power outages. These interactions will allow students to interact with other members of the community of practice. Researchers suggest that this engagement with members of the community allows the students to see themselves as peers with the electrical engineers versus a more formal relationship that happens between teachers and students. The teachers will then introduce and facilitate key points of the experiences that the electricians mentioned.

AR support: During the interaction session with the AR application, teachers will facilitate questions and answers to allow students to develop a strong sense of engagement with the narrative that the power is out in their home and the physical space of the classroom. The last role of the teacher is to illustrate circuit components using AR graphical representations and monitor the collaboration within the student groups for troubleshooting in case they encounter problems.

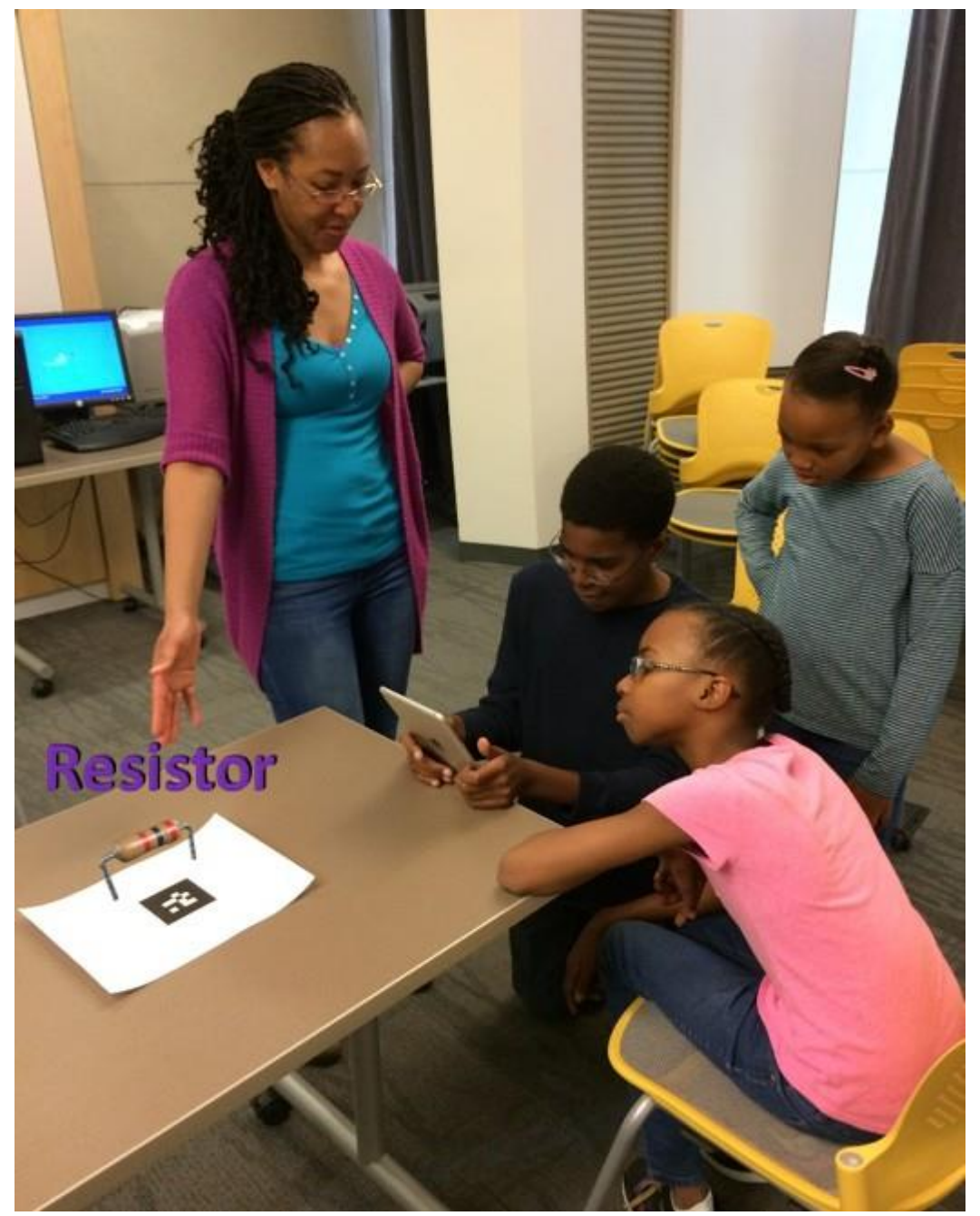

Figure 2. Teacher showing students a simulated $20 \mathrm{~K}$ ohm resistor 


\section{$\underline{\text { Student Roles }}$}

Instructional component: The student role is to become a larger participate in the learning, i.e. the student should move from an observational role to a contributing role. The simulated environment will allow students to learn skills used by engineers, helping to clarify students' understanding of what engineers do. They should feel a strong ownership that they are experts or becoming experts in the field of engineering. Students will be able to abstractly understand circuitry relative to how current flows through circuits by reading text and seeing 3D graphics of resistors, power supply, amplifier, etc. AR provides a multisensory approach to learning that links text, image, sound, and movement to support student collaboration.

Classroom Illustration: Students will form teams to explore circuitry in the classroom. Holding the AR application in front of local objects, e.g. light switches, outlets, or projectors, a 3D virtual circuit board will appear to display current flow. While participating in groups, students will have the opportunity to ask questions and clarify any questions they may have with their peers. Students should be encouraged to interact with the AR app, their peers, and to discover knowledge on their own. These opportunities allow students to become active members of the community.

AR support: The use of AR adds more meaning to topics that students may not experience in the real world. For example, students would normally not be able to see electrical circuits of an outlet, remove and replace components of a circuit, or be able to develop a solution to fix the problem. Interacting with augmented simulated circuits created by the AR, students will develop adequate problem solving skills and transferrable solving methods to apply what they learned in the classroom to different settings.

\section{Content Outcomes}

Instructional component: Students demonstrate that they have achieved outcomes when they can operate in the community with a full understanding of the "constraints and affordances" of the situation ${ }^{[7]}$. The unique affordances of AR include the greater fidelity of real world environments, the ability of team members to talk face-to-face on multiple dimensions, and the capacity to promote kinesthetic learning through rich spatial contexts ${ }^{[6]}$.

Classroom Illustration: To evaluate student outcomes, each student will create an incomplete circuit using AR representations, i.e., text, and graphics for their team members to correctly solve. Students will have the opportunity to facilitate troubleshooting and answer questions on content that their team members are struggling with. This allows for reinforcement of spatial understanding of current moving through a closed or open circuit. The affordance of this demonstration is the reassurance of the student becoming a member of the community in an authentic environment.

AR support: The AR application will facilitate student collaboration and interaction. Also, students will use the graphical content and textual information to see how components of the circuit interact with each other. Along with spatial reinforcement, students understand the constraints of circuit design by using the AR application to solve similar problems to power outages. 


\section{Class Activities}

Instructional component: Class activities should reflect problems faced by the community as much as possible, and create an authentic learning environment for students. The simulated environment is essential to the activity component because otherwise it may be hard for the students to envision circuitry and its components. More specifically, it can be difficult for students to envision current flow through a closed circuit or understand why the light bulb is out because it is not enough voltage in the power supply.

Classroom Illustration: During the class activity, students will diagnosis the previously discussed power outage scenario. They will learn how current moves through a circuit in relation to how circuit components are arranged. Once the students develop a solution to the power outage scenario, the teacher can create additional problems for the students to think about that extends past power outages. For example, teachers can have students imagine they need to charge their mobile devices and the outlet does not work. Looking at the circuitry of that outlet, students will determine if there was a shortage, missing component, or faulty wiring.

AR support: All the work performed during the class activities will be done in teams. Students will use the AR app to build and investigate the characteristics of parallel and series circuits. From these interactions, they will be able to tell the difference between open, closed and blown circuits. Once these skills are developed, the students can design a circuit diagram that will output enough current to produce light in Christmas light bulbs. Teachers can ask students to change or replace components to investigate if or what affect it would have on the circuitry. The AR application can direct the student to outlets and light switches in their immediate environment. At each outlet or switch, the AR application will display a 3D graphical simulated circuit. The students can be tasked to name each component and how it contributes to the circuitry.

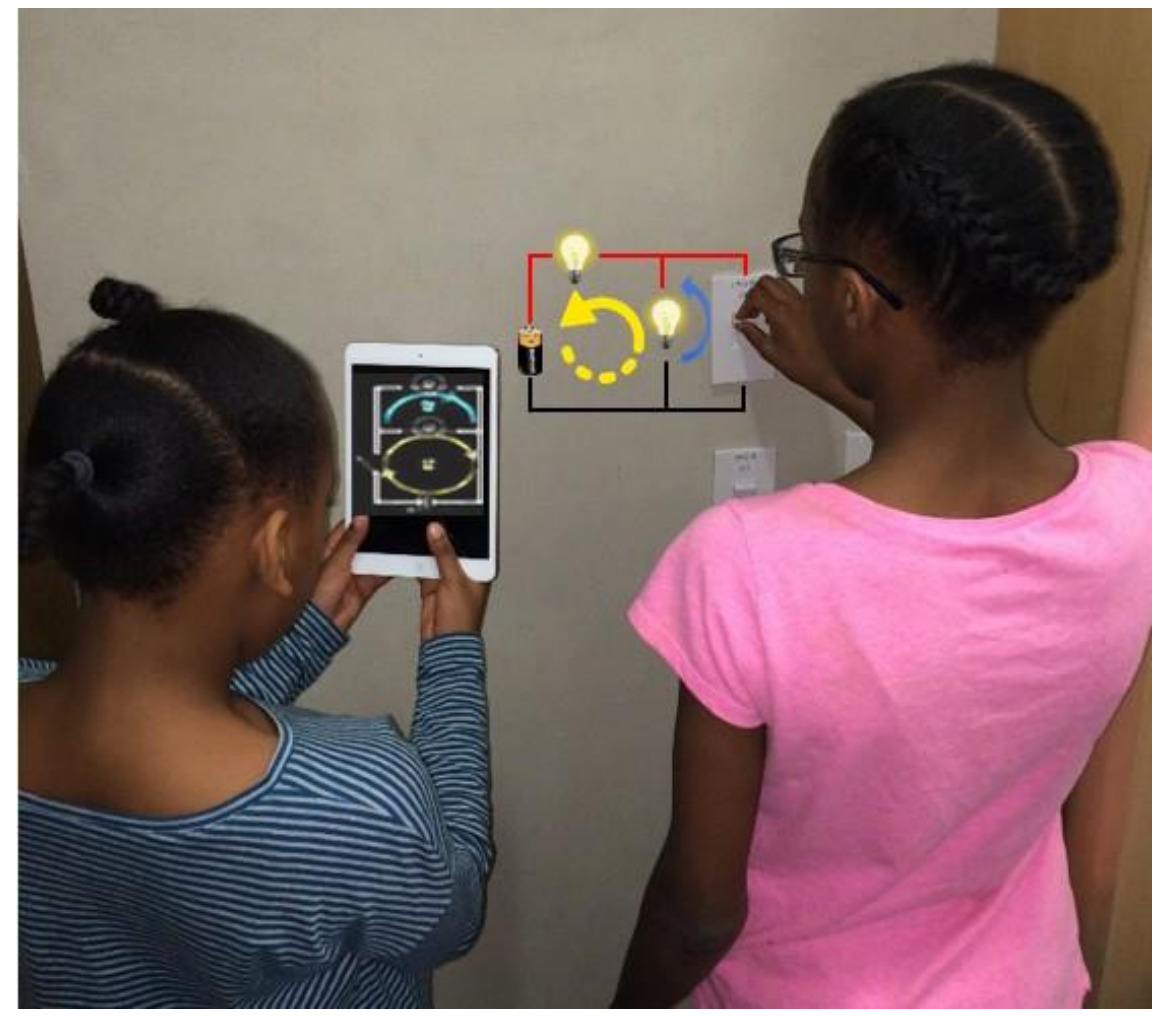

Figure 3. Students interacting with AR application during class activity 


\section{$\underline{\text { Assessment }}$}

Instructional component: Assessment occurs in the form of reflections e.g., portfolios or journaling. The major benefit for using portfolios, journals, and other forms of reflection is to see the approach that students take to solve a problem. Journals have the ability to show teachers the students' reactions to the concepts and class activities, solutions to problems, and document notes on potential ideas of how they can become members of the community. Similar to journaling, portfolios give teachers a deeper look into the student's understanding. This deeper look is the ability to evaluate the student's' progress at the end of a class activity and instructional sessions. Peer to peer assessment can also occur. Students can discuss journal and portfolio entries with each other, allowing them to hear a different perspective and see different examples of how their peers communicate what they have learned.

Classroom Illustration: Situative learning evaluates open-ended problems that have multiple solutions. However, this can be difficult to capture by using traditional methods such as exams. To collect this qualitative data, teachers could set time aside at the end of each unit for students to keep electronic records of their experiences with AR. In these electronic records, students could input text, photos, or audio directly in the AR application to document their ideas, thoughts, and reflection about the engineering concepts. In addition to storing the data for teacher use, this method supports peer-to-peer assessment. Students can exchange devices to review peer solutions and have paired "think aloud" sessions to share their problem solving approach verbally with their peers. In this way, students actively participate in formative assessment.

AR support: Assessment of students' reactions can be embedded in the AR application. While participating in class activities and instructional sessions, the AR application will collect performance data on the student. Some of this performance data may include the time it takes students to complete a circuit design or to solve a problem given to them by their classmates. The AR application can also record the interactions the students have with each other while there are in the collaborative teams. This provides an evaluation of students' comprehension as they progressively participate in the community of practice. Once this data is captured, it will be stored on a server for teachers to access and assess students' progress.

\section{Purpose of Grades}

Instructional component: Feedback occurs throughout the learning process to allow students to work through their difficulties. Grades are more qualitative in nature, e.g., written descriptions, and our assigned at the end of the project.

Classroom illustration: The AR application has the potential to provide students with immediate feedback. This is done by presenting the student with multiple-choice, fill in the blank, and sentence completion questions during class activities.

$A R$ support: The application will provide real-time scaffolding in lessons to accommodate student needs. In this way, the application will reveal more advanced functionality and problems as students' ability to master engineering concepts increases. The student will be provided an enriched learning experience because the AR application will adequately challenge students. This will support student understanding and achievement growth over time. In situating AR in classroom activities, we hope students will be able to describe how current flows through parallel and series circuit with various components being added or removed. The 
AR application allows students to envision the spatial relationship between diagram, circuits, and its components. Students will also be able to describe the connections among representations of circuit symbols. Overlaying the 3D graphics on electrical components create concrete examples for students. By illustrating current flow, abstracts concepts become more tangible. Lastly, student learning is connected to the community of practice by aligning the AR application with engineering professional practice and emphasizing design.

\section{Implications}

The intent of this paper was to present a guide for using an AR application embedded in situative learning theory to teach circuitry to fourth graders. Singularly using situated learning theory could increase students' engagement and interest towards engineering concepts by becoming practitioners of the community, but incorporating AR adds a new dimension by immersing the students in an augmented environment. As a result, we believe there are implications for both student learning and instructional design.

The enhanced learning environments will allow students to investigate concepts that may be too expensive, dangerous or logistically impossible to observe in the real world. These guidelines allow students to practice engineering concepts in real situations and conditions of professionals ${ }^{[14]}$. The combination of situated learning and AR is appropriate for engagement because it allows students to immerse themselves into the learning situation and create meaningful interactions among the students, teachers, community, and virtual objects within the context of the classroom.

The circuitry example used in the guide was inspired by a lesson plan on TeachEngineering.org, an open access digital library collection that offers post-secondary and pre-college teacher's lesson plans to teach science and math through engineering design curricula in K-12 ${ }^{[16]}$. By using Newstetter and Svinicki's conceptual frameworks and TeachEngineering.org, we illustrate how two prominent resources intended for post-secondary and pre-college engineering educators can be used by engineering faculty to base their K-12 technology applications in educational theory. This guide offers a time and cost-effective way for engineering faculty to merge their technical expertise with existing educational resources to improve their K-12 curriculum and outreach efforts.

\section{Future Work}

Our next steps are to prototype our AR application with fourth grade students using a circuitry lesson plan. Then, conduct a study that utilizes our proposed guidelines. This study will be conducted in a rural area of Virginia in a public school system. We will investigate what the benefits and challenges are for situating AR in the classroom, as well measure student learning outcomes. We anticipate our findings will provide guidelines for both teachers and engineering education researchers to employ and provide additional evidence for the usability of AR applications grounded in educational research.

\section{Conclusion}


Technology has been increasingly incorporated in the K-12 classroom to promote STEM interest and learning as collaborations with post-secondary and pre-college engineering educators continue to expand. Augmented reality is one technology application that has been used to support students learning a variety of STEM concepts. By overlaying 3D images on real objects, augmented reality can target improving engineering related student outcomes, e.g. spatial understanding ${ }^{[17],[18]}$.

We proposed that AR applications grounded in learning theory would foster instruction that aligns well with educational principles of how students learn and supports measurement of student learning outcomes. We presented guidelines that will help engineering faculty incorporate well-established research findings related to learning theory into AR application design. We illustrated this through discussing a guide that can be used to teach circuitry, a fundamental electrical engineering concept, to fourth graders within situative learning theory.

The use of augmented reality in the classroom has the ability to enhance the learning experience for K - 12 students by creating visual and tangible interaction applications that simulate real world problems. The National Educational Technology Plan of 2010 believes that one of the most powerful ways to transform and improve K-12 education is to instill a culture of innovation through technology use. By leveraging learning theory to inform implementation of AR applications in K-12, collaborations between post-secondary and pre college engineering educators can create well-designed and beneficial educational experiences.

\section{References}

[1] President's Council of Advisors on Science and Technology. (2012). Engage to excel: producing one million additional college graduates with degrees in science, technology, engineering, and mathematics. Washington, D.C.

[2] Seals, C. D., \& Smith, E. B. (2013, June), Enhancing K-12 Education with Engineering Outreach Paper presented at 2013 ASEE Annual Conference, Atlanta, Georgia. https://peer.asee.org/19545

[3] Shelton B (2003) Augmented reality and education: current projects and the potential for classroom learning. New Horizons for Learning. IX (1).

[4] Newstetter, W., \& Svinicki, M. (2014). Learning theories for engineering education practice and research. In A. Johri \& B. M. Olds (Eds.), CHEER: Cambridge Handbook of Engineering Education Research. New York, New York: Cambridge University Press.

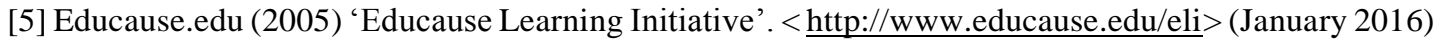

[6] B. Shelton, N Hedley. Using Augmented Reality for Teaching Earth-Sun Relationships to Undergraduate Geography Students. The First IEEE International Augmented Reality Toolkit Workshop. Darmstadt, Germany. September, 2002.

[7] Edelson, Daniel C., Douglas N. Gordin, and Roy D. Pea. "Addressing the challenges of inquiry-based learning through technology and curriculum design." Journal of the learning sciences 8.3-4 (1999): 391-450.

[8] National Research Council. Engineering in K-12 Education: Understanding the Status and Improving the Prospects. Washington, DC: The National Academies Press, 2009. doi:10.17226/12635

[9] K. Tan, E. Lewis, N. Avis, and P. Withers. Using augmented reality to promote an understanding of materials 
science to school children. In Proceedings of the ACM SIGGRAPH Asia Educators Programme, pages 1-8. ACM, 2008.

[10] Larsen, Y., Buchholz, H., Brosda, C., Bogner F. (2012) "Evaluation of a portable and interactive augmented reality learning system by teachers". Proceedings of the "Science Center To Go" Workshops. 41-50.

[11] Kapp, Karl M. The Gamification of Learning and Instruction: Game-based Methods and Strategies for Training and Education. San Francisco, CA: Pfeiffer, 2012.

[12] Greeno, J. G., Collins, A. M., \& Resnick, L. B. (1996). Cognition and learning. In B. Berliner \& R. Calfee (Eds.), Handbook of Educational Psychology (pp. 15-46). New York: MacMillan.

[13] Johri, A., \& Olds, B. M. (2011). Situated engineering learning: Bridging engineering education research and the learning sciences. Journal of Engineering Education, 100(1), 151-185.

[14] Wilson, Arthur L. "The promise of situated cognition." New directions for adult and continuing education 1993.57 (1993): 71-79.

[15] Tseng, T. B., \& Akundi, A., \& Saavedra, J. A., \& Smith, E. D. (2015, June), Augmenting High School Student Interest in STEM Education Using Advanced Manufacturing Technology Paper presented at 2015 ASEE Annual Conference and Exposition, Seattle, Washington. 10.18260/p.23608

[16] Teachengineering.org. (2004). 'Put a Spark in It! - Electricity '.

<https://www.teachengineering.org/view_curricularunit.php?url=collection/cub_/curricular_units/cub_electricity/cu b_electricity_curricularunit.xml> (January 2016).

[17]Thornton, T., Ernst, J. V., \& Clark, A.C. (2012). Augmented Reality as a visual and spatial learning tool in technology education. Technology and Engineering Teacher, 71(8), 18- 21.

[18]Kaufmann, H., \& Schmalstieg, D. (2003). Mathematics and geometry education with collaborative augmented reality. Computers \& Graphics,27(3), 339-345. 